\title{
High-Temperature Corrosion of Ni-Base Alloys by Waste Incineration Ashes
}

\author{
M. SoleckA*, J. Kusiński, A. Kopia, M. Rozmus-Górnikowska And A. Radziszewska \\ Department of Surface Engineering and Materials Characterisation, Faculty of Metals Engineering \\ and Industrial Computer Science, AGH University of Science and Technology, Krakow, Poland
}

$\mathrm{Ni}-\mathrm{Cr}-\mathrm{Mo}$ alloys, e.g. Inconel 625 and 686, exhibit high-temperature corrosion, oxidation and wear resistance. For this reason, these alloys are typically used as a coating material in different environments as effective solid-state diffusion barriers between the corrosive atmosphere and the base metal. To perform the Ni-base weld overlays, without introducing too much Fe, a new welding technique called cold metal transfer was used. High-temperature corrosion of boiler parts during incineration of waste was investigated. Boiler tubes were coated with Inconel 625 and Inconel 686 nickel alloys and, after subjecting them to waste incineration ashes, they were examined by scanning electron microscopy with energy dispersive X-ray spectrometer to reveal different corrosion mechanisms and their causes. Results indicate a strong dependence of the boiler steel corrosion on anions in the incineration waste ash. X-ray diffraction characteristics of the scale showed that surface corrosion processes induce the formation of $\mathrm{CrO}_{2}$, $\mathrm{NiO}$. The presence of iron in the clad weld surface is conductive to the formation of the $\mathrm{Fe}_{2} \mathrm{O}_{3}$ oxide.

DOI: 10.12693/APhysPolA.130.1045

PACS/topics: 81.05.Bh, 68.47.Gh, 68.37.Hk, 61.05.cp

\section{Introduction}

Ni-base superalloys like Inconel 625 and Inconel 686 are widely used in several industrial sectors, including petrochemical and power generation, due to their high performance in aggressive environments. Nowadays, Nibase alloys are typically used to manufacture engineering components, or coatings for protection of cheaper metallic substrates, which should work in extreme conditions, including mechanical loading and an aggressive environment at high temperature. Due to the excellent high temperature corrosion resistance and good strength at high temperatures Ni-base alloys can work in aggressive environments [1,2].

Inconel 625 is an austenitic alloy, showing an extraordinary combination of high temperature strength, toughness and surface stability in corrosive or oxidative environments. Due to such superior characteristics, it is a very important material for high temperature applications such as aerospace and power generation industries. Because of its corrosion resistance, high strength and creep strength, it is used in the aerospace, chemical, power plant and marine applications. Alloy 625 is designed to initially gain high temperature strength by solid solution hardening, brought about by Mo and $\mathrm{Nb}$ elements in $\mathrm{Ni}-\mathrm{Cr}$ matrix. However, although designed to initially gain strength by means of solid solution, it is seen that the intermetallic phases and carbides precipitate in it through ageing treatments performed in the temperature range of $550-750^{\circ} \mathrm{C}[3,4]$.

Inconel 686 is a nickel-chromium-molybdenumtungsten advanced corrosion resistant austenitic alloy

\footnotetext{
*corresponding author; e-mail: msolecka@agh.edu.pl
}

that offers outstanding resistance to oxidizing, reducing, and mixed acid environments, including those containing halides. The alloy is resistant to seawater and other marine environments. Thus, alloy 686 is widely used in the chemical processing, marine, and air pollution control (flue gas desulphurization) industries. The alloy's resistance to a diverse number of environments makes it a candidate for many aggressive aqueous environments. This document is written to help design and maintenance engineers evaluate materials and compare the corrosion resistance of alloy 686 with the other corrosion-resistant alloys currently available. Among a variety of hard facing techniques, cladding is another form of surface treatment, where the bulk material surface is given a protective layer of another material $[5,6]$. The clad layer has superior properties than those of the bulk material. Chemical composition of the clad layer should be homogeneous and the concentration of $\mathrm{Fe}$ entering from the base material into the coating should be as low as possible $[7,8]$. To produce Ni-base weld overlays, without introducing too much $\mathrm{Fe}$, a new weld technique called cold metal transfer (CMT) was used $[9,10]$.

Corrosion is particularly dangerous in the system of reaction-product ash components in the case of lowmelting eutectic formation. This phenomenon occurs primarily during combustion of heavy oils, resulting in the formation of ashes containing dangerous oxides, sulphides, chlorides. These ashes are deposited on components, causing serious damage to the material [11, 12]. In the flue gas containing the ashes, in addition to the processes of creating oxides, sulphides and chlorides, corrosion processes can take place with the participation of some ash components, with the originally formed plastic scale on the material surface. The products so formed may again react with components of the combustion gases. In this way a complex series of interacting 
heterogeneous reactions $[11,12]$ is formed. The reaction products of some ash components are particularly dangerous because they will cause catastrophic corrosion. In this case, after initial period of the induction state, the corrosion process starts very quickly. Ashes differ significantly among themselves in their content of aggressive components. For example - ashes containing chlorine [11] have a remarkably aggressive nature. The chemical composition of the ash deposits on particular metallic parts depends on the temperature of the exhaust. Therefore the distribution of the aggressive components at each site is uneven. The ash layer shows differences in chemical composition and relates to the temperature gradient. The mechanism resulting from the corrosive ash components' interaction is extremely complex. Different aggressive components interact with different mechanisms. It depends also on the reaction conditions and type of substrate which is exposed to the corrosive environments [13].

\section{Experiments}

Samples for the experiments were cut from original boiler tubes and had a shape of rectangular plates with dimensions $20 \mathrm{~mm} \times 5 \mathrm{~mm} \times 1.5 \mathrm{~mm}$ (length $\times$ width $\times$ thickness). The external surfaces of specimens were made of Inconel 625 and Inconel 686 alloys which were deposited on the boiler pipes made of $16 \mathrm{Mo} 3$ steel by the CMT technique. Samples were polished with sand paper, but no attempt was made to make it mirror-smooth. The Inconel 625 and 686 weld overlays samples were exposed to a high temperature environment - at $650{ }^{\circ} \mathrm{C}$ for $1000 \mathrm{~h}$ in the waste incinerations ashes.

The microstructure and chemical composition of Inconel overlays were investigated on sample cross-sections with a SEM, FEI Nova NanoSEM 450 equipped with an energy dispersive X-ray spectrometer (EDS) using EDAX equipment. The changes in elemental distribution were studied using the linear EDS analysis perpendicular to dendritic structure in overlays. Phase analysis of the corrosion products and the scales on the surface of the attacked specimens were studied by X-ray diffraction technique using PANanalytical Empyrean DY 1061 diffractometer using filtered $\mathrm{Cu} K_{\alpha} \lambda=1.54060$ Åradiation at $40 \mathrm{kV}$ and $40 \mathrm{~mA}$. The X-ray diffraction measurement were made with the Bragg-Brentano geometry in the range $2 \theta=20-100^{\circ}$. The step size and the time per step are respectively fixed at $0.05^{\circ}$ and $10 \mathrm{~s}$. The X-ray diffraction spectra were recorded with PANalytical HighScore Plus software.

\section{Results and discussion}

The microstructure and characteristics of weld overlays alloys Inconel 625 and 686 have been examined and discussed in publications $[3,14,15]$. The ashes used in this study were sampled from a fluidized bed waste incinerator. The ash analysis and chemical compositions of the waste incineration ashes are shown in Fig. 1. The X-ray analysis (Fig. 1b) indicated that major phases in ashes are $\mathrm{Ca}\left(\mathrm{CO}_{3}\right)$ and $\mathrm{SiO}_{2}$. The major elements of this waste incineration were: calcium (23.5 wt\%), oxygen (37.5 wt \%), silicon (22 wt\%), chlorine (2 wt\%) and potassium $(1.5 \mathrm{wt} \%)$ - Fig. 1c. The X-ray analysis (Fig. 1b) indicated that the major phases in ashes are $\mathrm{Ca}\left(\mathrm{CO}_{3}\right)$ and $\mathrm{SiO}_{2}$.
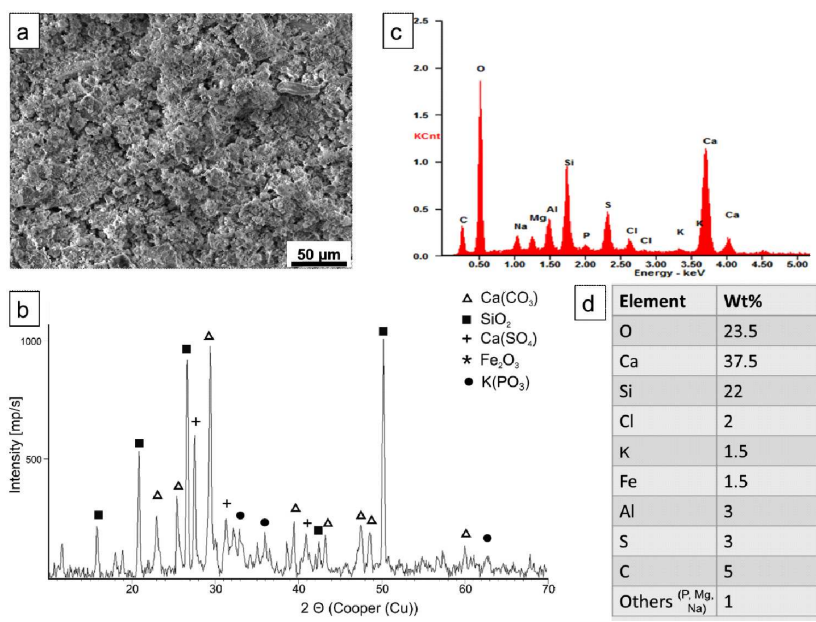

Fig. 1. Ashes in waste incineration: (a) image in ashes, (b) chemical compositions, (c) spectrum by EDS of these ashes.

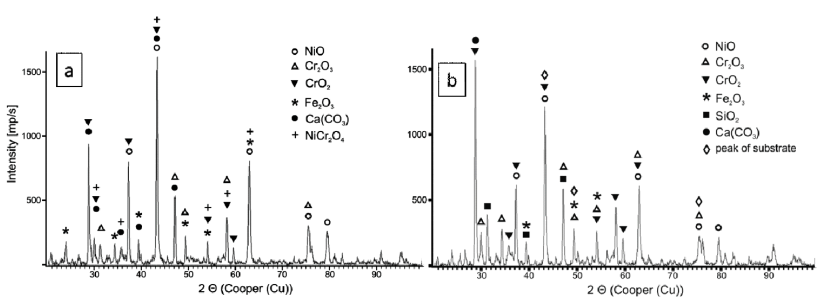

Fig. 2. X-ray diffraction analysis of $\mathrm{Ni}-\mathrm{Cr}-\mathrm{Mo}$ alloys after corrosion test at $650^{\circ} \mathrm{C}$ by $1000 \mathrm{~h}$ : (a) Inconel 625 , (b) Inconel 686 .

The X-ray diffraction patterns of the surfaces of the corroded specimens Inconel 625 and 686 are presented in Fig. 2. The identified phases, which demonstrated the best match with the diffraction peaks of the obtained XRD patterns, are also listed in Fig. 2a,b. XRD patterns of the phases were compared with standard patterns to graphically show the phase match, confirming the presence of all the identified phases.

Corresponding to the Inconel $625 \mathrm{XRD}$ pattern in Fig. 2a after corrosion, three of the characteristic phases are the oxides $\mathrm{CrO}_{2}$ and $\mathrm{Cr}_{2} \mathrm{O}_{3}$ and $\mathrm{NiO}$. This is an important observation confirming that the $\mathrm{CrO}_{2}, \mathrm{Cr}_{2} \mathrm{O}_{3}$ protective layer of the weld overlay alloy 625 is capable of providing partial protection passivation layers which reduce the corrosion rate for the weld overlay, when the overlay is exposed to waste incineration ashes medium at $650{ }^{\circ} \mathrm{C}$. Also cladded weld Inconel 625 scale showed that surface corrosion processes induce the formation of stoichiometric $\mathrm{NiCr}_{2} \mathrm{O}_{4}$, and $\mathrm{Ca}\left(\mathrm{CO}_{3}\right)$ phases. The presence of iron in the cladded weld surface is conducive to the formation of $\mathrm{Fe}_{2} \mathrm{O}_{3}$ oxide phase, which worsens 
the weld's resistance to corrosion. Figure 2b shows Inconel $686 \mathrm{XRD}$ pattern after corrosion. The following phases were identified: $\mathrm{NiO}, \mathrm{Cr}_{2} \mathrm{O}_{3}, \mathrm{CrO}_{2}, \mathrm{Fe}_{2} \mathrm{O}_{3}$, and $\mathrm{Cr}_{0.4} \mathrm{Ni}_{0.64}$ which comes from the substrates (peak of substrate). Also in this material $\mathrm{Fe}_{2} \mathrm{O}_{3}$ oxide was observed before the corrosion test, which worsens the resistance to corrosion of the welds. $\mathrm{SiO}_{2}$ and $\mathrm{Ca}\left(\mathrm{CO}_{3}\right)$ (Fig. 2b) in this material came from the corrosive medium - ashes in waste incineration.
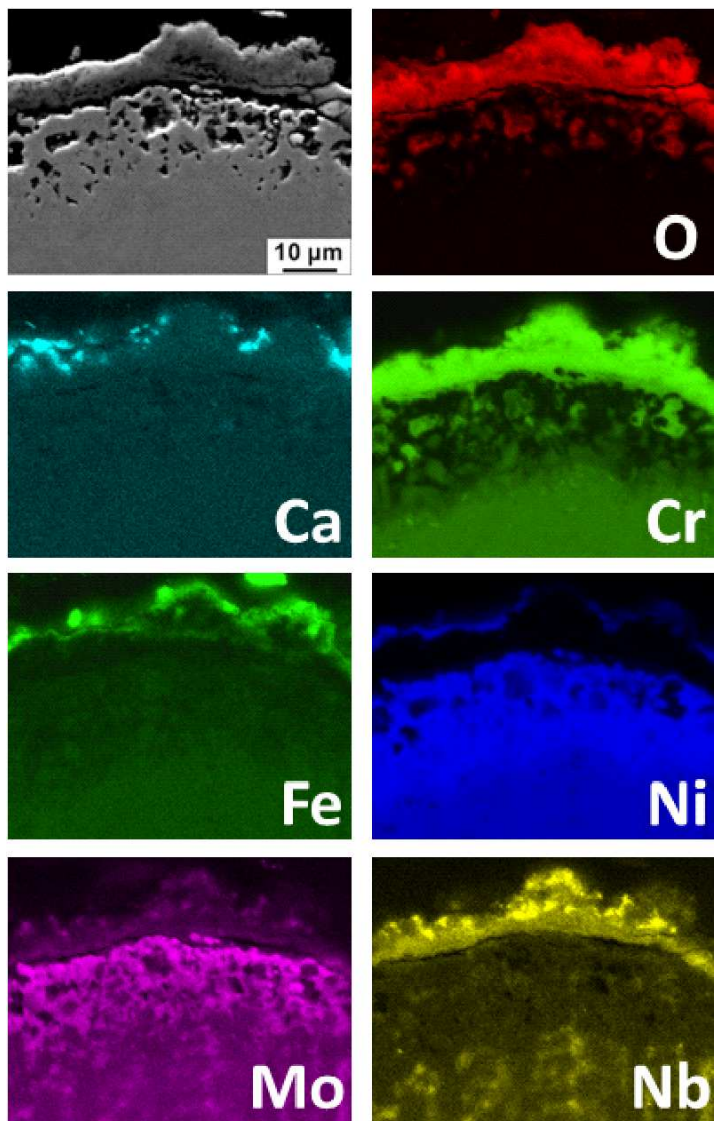

Fig. 3. Cross-sectional X-ray mapping results for Inconel 625 , distributions of selected elements: $\mathrm{O}, \mathrm{Fe}, \mathrm{Ni}$, $\mathrm{Ca}, \mathrm{Cr}, \mathrm{Mo}, \mathrm{Nb}$.

Figures 3 and 4 present the cross-sectional X-ray mapping results, which graphically show the cross-sectional distributions of the elements: $\mathrm{Ni}, \mathrm{Cr}, \mathrm{Mo}, \mathrm{Nb}, \mathrm{Fe}, \mathrm{Ca}$, and $\mathrm{O}$ in Inconel 625 (Fig. 3), the same elements were found in Inconel 686, with $\mathrm{Nb}$ being replaced by $\mathrm{W}$ (Fig. 4). Fe-rich scale, Cr-rich scale, as well as the Nirich $/(\mathrm{Cr}, \mathrm{Fe})$-depleted layer were formed underneath the Cr-rich scale. The Ni-rich scale formed directly on the surface of the alloy 625 (Fig. 3) and Inconel 686 (Fig. 4) weld overlay, underneath the Fe-rich scale. By comparing the cross-sectional X-ray maps it was seen that both the Fe-rich and the Cr-rich scales were also rich in oxygen. Formation of $\mathrm{Ca}\left(\mathrm{CO}_{3}\right)$ oxide at the surface of both alloys (Fig. 3 and 4 for Inconel 625 and 686, respectively) is also confirmed by X-ray diffraction pattern (Fig. 2a,b). $\mathrm{Ca}\left(\mathrm{CO}_{3}\right)$ originates from ashes used in corrosion test.
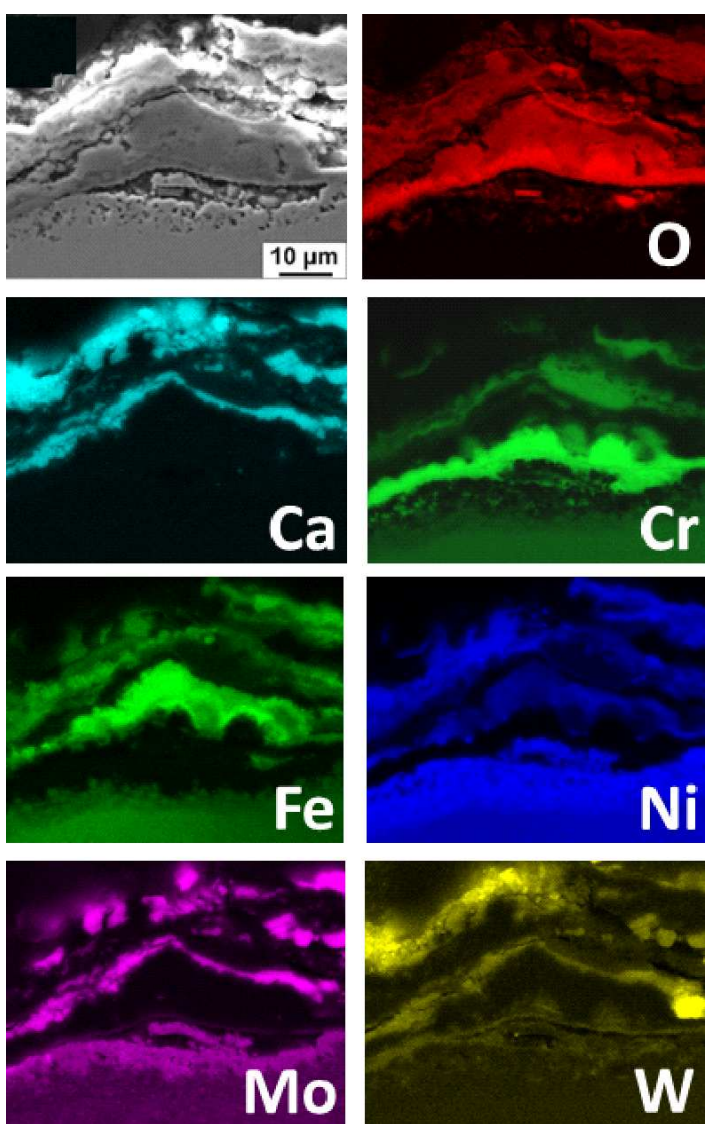

Fig. 4. Cross-sectional X-ray mapping results for Inconel 686 , distributions of selected elements: $\mathrm{O}, \mathrm{Fe}, \mathrm{Ni}$, $\mathrm{Ca}, \mathrm{Cr}, \mathrm{Mo}, \mathrm{W}$.

\section{Conclusions}

The results from this study have yielded valuable information that can be applied to waste incineration plants which have corrosive environments. In both cases, the clad layer of Inconel 625 and Inconel 686, after oxidation in ashes from the incineration of waste during $1000 \mathrm{~h}$, facilitates the formation of $\mathrm{Ni}$ and $\mathrm{Cr}$ oxide films on the surface of the oxide layer. The protective oxide layer for Inconel 625 is a mixture of $\mathrm{Cr}_{2} \mathrm{O}_{3}$ and $\mathrm{NiCr}_{2} \mathrm{O}_{4}$ while $\mathrm{Cr}_{2} \mathrm{O}_{3}$ is identified as the main protective oxide layer in alloy. A thin film of nickel oxide appears on the surface, followed by a $\mathrm{Cr}_{2} \mathrm{O}_{3}$ and $\mathrm{CrO}_{2}$ which protect the material from the harmful ashes actions in Inconel 686 . The coating components Inconel 625 alloy shows a faster diffusion process in the core than Inconel 686 clads layers. This is related to $\mathrm{Mo}$ and $\mathrm{Nb}$ in the alloy Inconel 625, which segregate to the interdendritic region, whereas Inconel 686 alloy exhibits a greater homogeneity of the structure.

\section{Acknowledgments}

The project was financed by National Science Centre, Poland. Grant number DEC-2014/15/N/ST8/02625. 


\section{References}

[1] C.E. Stevens, R.W. Ross, J. Mater. Energy Syst. 8, 7 (1986).

[2] S. Mrowec, T. Weber, Modern Heat Resistant Materials, WNT, Warszawa 1968 (in Polish).

[3] M. Solecka, P. Petrzak, A. Radziszewska, Solid State Phenom. 231, 119 (2015).

[4] O.H. Madsen, in: Proc. 4th Int. Symp. on Waste Treatment Technologies, Sheffield (UK), Babcock and Wilcox Volund, Sheffield 2003, p. 1.

[5] J.L. Barna, K.B. Rivers, PAPTAC 25-29, 1 (1999).

[6] L. Young-Ho, I.-S. Kim, Wear 253, 438 (2002).

[7] M. Rozmus-Gornikowska, L. Cieniek, M. Blicharski, J. Kusinski, Arch. Metall. Mater. 59, 1081 (2014).

[8] C.G. Pickin, S.W. Williams, M. Lunt, J. Mater. Process. Technol. 211, 496 (2011).
[9] Marketing materials Fronius company, CMT: Cold Metal Transfer - MIG/MAG dip-transfer arc process, www.fronius.com.

[10] J. Bruckner, Przeglad Spawalnictwa 7-8, 24 (2009) (in Polish).

[11] S. Kameswari, J. Therm. Anal. 36, 23 (1990).

[12] U.K. Chatterjee, S.K. Bose, S.K. Roy, Environments Degradation of Metal, Marcel Dekker, New York 2001.

[13] S. Mrowec, T. Weber, Gas Corrosion of Metals, Wyd. Śląsk, Katowice 1975 (in Polish).

[14] P. Petrzak, M. Blicharski, S. Dymek, M. Solecka, Solid State Phenom. 231, 113 (2015).

[15] J. Kusiński, M. Blicharski, Ł. Cieniek, S. Dymek, M. Rozmus-Górnikowska, M. Solecka, Inżynieria $\mathrm{Ma}$ teriatowa 208, 363 (2015) (in Polish). 